\title{
PODER, DOMINAÇÃO E VIOLÊNCIA: \\ UMA LEITURA DE INSTINTO
}

\section{POWER, DOMINATION AND VIOLENCE: A READING OF INSTINCT}

\section{Clarice Braatz Schmidt Neukirchen ${ }^{1}$}

Resumo: Objetiva-se, neste artigo, tecer considerações sobre o filme "Instinto" (1999), dirigido por Jon Turteltaub, observando como os questionamentos acerca do processo civilizatório, das formas de dominação e de controle existentes na sociedade arquiteturam essa obra cinematográfica. A partir da análise de diferentes metáforas presentes no filme, buscarse-á discutir a questão das relações de poder, o jogo que se estabelece em sociedade por meio da linguagem e as ideologias que se manifestam por meio dos comportamentos dos atores sociais em suas atuações cotidianas, enfatizando-se a linguagem como um dos principais instrumentos a serviço da perpetuação das regras estabelecidas pela sociedade "civilizada".

Palavras-chave: linguagem; sociedade; poder; dominação; resistência.

Abstract: In this article, we propose to make considerations about the film "Instinct" (1999), directed by Jon Turteltaub. It was observed how the questions about the civilizing process, the forms of domination and control existing in society compose this cinematographic work. Based on the analysis of different metaphors present in the film, we will discuss the question of power relations, the dynamics established in society through language and the ideologies which are manifested through the behaviors of social actors in their everyday acts Language was emphasized as one of the main instruments at the service of the perpetuation of the rules established by the "civilized" society.

Keywords: language; society; powe; domination; resistance.

\section{Introdução}

Pretende-se, com este artigo, apresentar considerações acerca de como as relações sociais e o processo civilizatório pelo qual passa o indivíduo são marcados por relações de dominação. Para tanto, será utilizado como objeto de análise o filme "Instinto" (1999), de Jon Turteltaub. O trabalho de investigação do tema proposto amparou-se nos pressupostos autores como Mikhail Bakhtin (1999), Michel de Certeau (2001) e Michel Foucault (1987).

A linguagem será abordada a partir de sua função de mediadora nas/das relações de interação humana, isto é, como recurso que se torna útil na manutenção de relações de dominação e poder. Na visão de Bakhtin (1999), não existe atividade mental sem expressão

\footnotetext{
${ }^{1}$ Mestre pela Universidade Estadual do Oeste do Paraná (UNIOESTE). Docente da UNIOESTE. E-mail: claricebraatz@yahoo.com.br
} 
semiótica, isto é, todo homem pensa e fala a partir signos coletivamente construídos que são, por assim dizer, armazenados na mente humana. As unidades de sentido não são propriedades interiores de um único indivíduo, antes pertencem à coletividade, sendo as enunciações reguladas por fatores externos ao indivíduo. Para Bakhtin (1999), toda enunciação demonstra crenças, valores morais, preconceitos e tabus, ou seja, ideologias do locutor, que são o reflexo das ideologias dos grupos sociais nos quais ele se insere. A utilização da linguagem será abordada, assim, sob este aspecto de deflagrador de ideologias, entendendo o conceito de ideologia não apenas no sentido marxista do termo, isto é, como um conjunto de idéias falsas que ajudam a legitimar o poder de quem domina, mas como um conjunto de idéias, falsas ou não, que caracterizam um grupo de indivíduos, uma classe social ou algo mais amplo como, por exemplo, uma nação.

O Filme apresenta a história do antropólogo americano Ethan Powell (Anthony Hopkins) que, após viver dois anos entre gorilas, mata dois guardas florestais em uma floresta africana, na tentativa de proteger os gorilas que estavam sendo sacrificados pelos guardas florestais. Ethan então é preso e deportado para seu país de origem, Estados Unidos, sendo encarcerado na penitenciária Harmony Bay. Uma vez encarcerado, nega-se a falar, sendo, por isso, submetido a tratamento com o psiquiatra Theo Caulder (Cuba Gooding Jr.). A partir da relação estabelecida com o psiquiatra, Ethan passa a se comunicar com o mesmo por meio da palavra verbal, bem como por meio de outros sistemas de signos, como, por exemplo, desenhos na parede. $\mathrm{O}$ filme termina com a fuga de Ethan e seu retorno às florestas africanas.

\section{0 louco psicopata}

O tema central do filme esconde-se por detrás de uma série de metáforas. Ethan pode ser considerado a principal destas metáforas, pois representa o homem excluído da sociedade civilizada por pensar e agir de forma distinta da forma imposta por cua comunidade. Ethan é o "psicopata" que mata dois guardas florestais em uma floresta africana onde vivia cercado por gorilas e, após ser preso e deportado para seu país de origem, cala-se, fugindo de todas as formas possíveis dos convencionalismos impostos pela sociedade civilizada.

De acordo com Emile Durkheim, a sociedade se manifesta como um organismo vivo, exterior aos indivíduos, sendo as formas de agir, pensar e sentir dos homens exteriores aos sujeitos e determinados pelo poder coercivo da sociedade, sendo possível definir coerção social como

a força que os fatos exercem sobre os indivíduos, levando-os a conformar-se às regras da sociedade em que vivem, independentemente de sua vontade e escolha. 
Essa força se manifesta quando o indivíduo adota um determinado idioma, quando se submete a um determinado tipo de formação familiar ou quando está subordinado a determinado código de leis (COSTA, 1997, p. 59).

Para Durkheim, o estado seria o órgão encarregado de dirigir as condutas individuais, por meio de representações sociais e coletivas. Os indivíduos não teriam o poder de optar frente ao direcionamento dado pela sociedade. Pressupõe-se, desta forma, uma espécie de individualidade nula. O progresso da sociedade, neste prisma, seria decorrente de uma ordem natural de desenvolvimento. Nesse âmbito, noções classificatórias, regras, conceitos e representações possuiriam natureza essencialmente social. Surgiriam a partir da necessidade de estabelecer regras gerais a uma sociedade. Ao referir-se a categorias de conhecimento e conceitos, Durkheim salienta que,

\begin{abstract}
se eles são comuns a um grupo social inteiro, não é que representem uma simples média entre as representações individuais correspondentes; pois então eles seriam mais pobres que estas últimas em conteúdo intelectual, enquanto que em realidade eles são prenhes de um saber que ultrapassa o de um indivíduo médio. Eles não são abstratos que só teriam realidade nas consciências particulares, mas representações tão concretas quanto aquelas que o indivíduo pode fazer-se de seu meio pessoal: correspondem à maneira pela qual esse ser especial que é a sociedade pensa as coisas de sua experiência própria (DURKHEIM, 1978, p. 236).
\end{abstract}

Até mesmo a capacidade de idealizar do homem seria, na visão de Durkheim, de natureza social. Segundo ele, teria sido "na escola da vida coletiva que o indivíduo aprendeu a idealizar" (1978, p. 226). Para Durkheim, "quem faz o homem é este conjunto de bens intelectuais que constitui a civilização e a civilização é obra da sociedade" (1978, p. 223), salientando que "um homem que não pensasse por conceitos não seria homem, pois não seria um ser social" (1978, p. 239). A consciência humana seria formada, assim, a partir destas categorias, exteriores e preexistentes ao indivíduo.

A linguagem, para Durkheim, seria um dos veículos de inter-relação entre os indivíduos. Seria, como os conceitos, algo cristalizado, que muda muito lentamente. Estaria diretamente ligada à consciência, haja vista que, segundo Durkheim, "o sistema de conceitos com o qual pensamos na vida corrente é aquele que exprime o vocabulário de nossa língua materna, pois cada palavra traduz um conceito" (1978, p. 235). Ora, a língua materna é algo que preexiste ao nascimento do indivíduo. Ela é apreendida por meio da interação social, logo, é, assim como os conceitos, algo exterior ao indivíduo e de cunho essencialmente social. Na visão de Durkheim, "a conversação, o comércio intelectual entre os homens consiste numa troca de conceitos. O conceito é uma representação essencialmente impessoal: é por ele que as inteligências humanas se comunicam" (idem, ibidem). E ainda: 
os conceitos com os quais pensamos correntemente estão consignados no vocabulário. Ora, não é duvidoso que a linguagem e, por conseguinte, os sistemas de conceitos que ela exprime seja o produto de uma elaboração coletiva. O que ela exprime é a maneira pela qual a sociedade em seu conjunto se representa os objetos da experiência. As noções que correspondem aos diversos elementos da língua são pois representações coletivas (DURKHEIM, 1978, p. 236).

Durkheim, inclusive, salienta que as mudanças na linguagem preestabelecida seriam uma espécie de violência feita "às maneiras de pensar instituídas” (1978, p. 235). Ora, no filme em análise é justamente a individualidade do ser humano que é colocada em questionamento. Ou seja, o filme discute a padronização, massificação, que nega ao indivíduo o direito a ser aceito caso não esteja enquadrado no sistema, bem ao gosto da visão durkheimiana de que todo aquele que é diferente constitui doença no corpo social.

Ethan é a "célula cancerígena" no corpo social descrito em Instinto. Pressupõe-se, inicialmente, que os gorilas sejam a origem da violência que Ethan pratica. Com o desenrolar do filme, no entanto, percebe-se que o que levou Ethan a praticar os assassinatos foi o instinto de preservação familiar, já que passara a fazer parte do grupo de gorilas. Apesar de ser aceito pelo bando, fica bem claro no filme que Ethan não deixou de ser homem. O filme demonstra que não foi tornar-se igual aos gorilas que o fez parte do grupo, mas o fato de ser aceito, apesar das diferenças. Ethan aprende com os gorilas o princípio da aceitação e da tolerância com o diferente, o que possibilita a harmonia e a segurança. Discute-se assim, na película, a aceitação e o respeito com a diferença. A possibilidade de coexistência harmônica mesmo sem a homogeneização.

O que gera o acesso de violência de Ethan é o fato de ver os guardas florestais - que deveriam defender os animais com que ele convive - matando os gorilas que haviam se tornado sua família. Nesta perspectiva, a violência não teria sido gerada por instintos animais, mas pela crueldade dos guardas florestais que agiram não por instinto, mas intencionalmente. Instaura-se, assim, o questionamento: quem é mais cruel: o irracional ou o racional? O que age por instinto ou intencionalmente? Vale ressaltar que os guardas florestais representam, no enredo, justamente o homem civilizado.

Ocorre a utilização, no filme, do enunciado "um dia na cidade é mais perigoso que um dia na floresta", demonstrando que a violência está mais presente na vida civilizada do homem do que na vida selvagem, não civilizada. Para Certeau, a violência nasceria do descrédito do indivíduo frente aos sistemas institucionais, vez que

a violência nasce, inicialmente, de uma rebelião contra as instituições e as representações que se tornaram 'não-críveis'. Ela recusa o não-significado. Ela diz não ao absurdo. Ela defende um 'outro país', privado de signos e desprovido de 
direitos - esse país estrangeiro que as exigências da consciência constituem e onde se buscam razões comuns para viver (CERTEAU, 2001, p. 33).

Nessa perspectiva, é possível afirmar que Ethan sofre uma espécie de ressocialização entre os gorilas, vez que sua interação com os primatas mudou seu conceito acerca de liberdade, família, aceitação, tolerância, respeito, dominação, etc., aproximando-o da representação de um homem "primitivo", "natural", despido das hipocrisias do mundo capitalista e "civilizado". Ethan é, assim, a metáfora da resistência frente aos sistemas de dominação socialmente estabelecidos, desprovido de sentido, recusando o "não-significado".

\section{Entre a palavra e o silêncio}

A principal personagem do filme, Ethan Powell, nega-se a falar após ser preso pelo assassinato de dois guardas florestais. $\mathrm{O}$ ato de não falar é uma das formas que a personagem encontrou de negar e, ao mesmo tempo, de fugir do sistema de dominação presente na sociedade dita civilizada, que tem no sistema linguístico uma de suas mais fortes representações. Ethan pode ser considerado análogo ao emigrante de que fala Certeau, o qual, tentando fugir da forma como a sociedade se configura, adota uma posição extrema. O não falar pode ser entendido como uma posição extrema adotada pela personagem.

Consoante a teoria bakhtiniana, toda enunciação implica na existência de um locutor e um interlocutor, sendo que a palavra é o produto da interação entre ambos. Conforme afirma Bakhtin, "a palavra é uma espécie de ponte lançada entre mim e os outros" (BAKHTIN, 1997, p. 113). Nesse sentido, o ato de não se comunicar apresenta-se como uma forma de resistência frente aos padrões éticos da sociedade, pois, ao não interagir com os outros indivíduos, Ethan mantém-se fora do "jogo que se joga na sociedade" por meio da linguagem. Vale mencionar, aqui, o pressuposto bakhtiniano segundo o qual, enquanto consciência, o signo seria uma ficção, ou seja, enquanto presa ao indivíduo, a consciência não possuiria força social. A partir da interação, no entanto, a consciência tornar-se-ia um "fato objetivo com força social imensa", ou seja, a partir do momento em que é exteriorizada, a consciência deixa de ser individual para tornar-se um fato social. $\mathrm{O}$ ato de falar seria a comprovação de que Ethan faz parte desta sociedade que o aprisionou. Logo, Ethan silencia. Segundo afirmação de Certeau, “cada vez mais opaca, uma vida marginalizada não se reflete mais em nosso sistema de representações. Campo e cidade - e não somente sindicatos e universidades - são povoados de silenciosos. Não por carecerem de idéias e de discernimento" (2001, p. 32).

Ao falar com Theo, Ethan demonstra que encontrou neste o interlocutor ideal, isto é, o interlocutor a quem pode dirigir o que tem a dizer, haja vista Theo ter motivos para lhe ouvir 
e lhe dar crédito. Nesta perspectiva, pode-se observar que Ethan cala-se não somente para se refugiar do mundo civilizado, mas também por não ter direito à palavra, pois a sociedade civilizada nega este direito aos excluídos. Somente um psiquiatra, a quem a sociedade permite que seja dirigido o discurso de um desequilibrado, serve como interlocutor para Ethan. Citando Norbert Elias,

Comunicação, transmissão de saber - de grupo para grupo ou de indivíduo para individuo - e consequentemente também a recusa de transmitir um saber, nunca dizem respeito apenas ao aspecto cognitivo das relações humanas, mas incluem sempre as relações de poder (ELIAS, 2000, p. 208).

Ora, é flagrante na película que a comunicação envolve relações de poder. Segundo Bakhtin, após o individuo expressar-se, sempre haverá uma reação do interlocutor, reação esta que, de alguma maneira, interferirá nas próximas enunciações, podendo gerar, inclusive, inibição e bloqueio no locutor. Levando em conta este pressuposto, é plausível afirmar que Ethan elege somente Theo como interlocutor pois sabe que a sociedade que o aprisionou não o compreenderia, haja vista ser ele a representação do anormal, daquele que foge às regras impostas pelo meio social. Ethan tem consciência de que seu discurso não terá validade para os interlocutores, haja vista que ao ser considerado um psicopata, mesmo sendo um antropólogo renomado, seu discurso perde a relevância social. A importância que a posição social do indivíduo dá a seu discurso pode ser observado, também, no pedido que Ethan faz para o psiquiatra, de que este narre sua história a todos a quem for possível, pois Theo teria o crédito necessário da sociedade para ser ouvido. Ressalta-se, aqui, a afirmação de Certeau de que "o que dá autoridade em uma sociedade toma uma destas duas figuras: discursos (obras, textos), ou então pessoas (que são também representantes)" $(2001,36)$.

Assim, a mudez de Ethan pode ser encarada como uma metáfora da resistência da personagem frente aos padrões morais, éticos e de dominação estabelecidos no interior da chamada civilização, bem como a perda de direito à palavra que sofre todo aquele que foge dos padrões preestabelecidos como normais em uma dada sociedade.

\section{Civilidade e sensatez}

Theo Caulder, o psiquiatra designado para atender ao caso de Ethan, é a representação do indivíduo que joga o jogo imposto pela sociedade. Diz o que é mais conveniente em cada momento, comporta-se conforme as regras e padrões preestabelecidos, ou seja, age da forma 
que a sociedade julga necessária para ser respeitado e obter sucesso. Apesar de concordar com a forma de pensar de seu paciente, Theo submete-se aos convencionalismos para preservar-se.

Observa-se que Theo mantém uma forma distinta de comunicação nos diferentes grupos com que interage. Por exemplo, ao conversar com seu professor, utiliza-se de uma forma respeitosa, gentil, quase submissa. Isto se dá tanto por ser o professor um "superior", quanto por causa da situação imediata, haja vista que Theo deseja persuadir o professor a the dar o caso de Ethan, ou seja, há nos atos de fala de Theo um discurso argumentativo com o intuito de persuadir.

$\mathrm{Na}$ interação com Ethan, também há, inicialmente, um jogo de persuasão, o que ocorre não somente por meio de palavras, mas também através de outras estratégias, como as fotos que Theo entrega a Ethan. Já na cena em que Theo é dominado por Ethan, por meio da violência física, a enunciação do psiquiatra passa a ser dirigida pela chamada "ideologia do cotidiano", pressuposto bakhtiniano, segundo o qual, em alguns momentos, os indivíduos seriam regidos não por sistemas de valores preestabelecidos, mas por necessidades imediatas que, no caso de Theo, seria sobreviver ao ataque violento de Ethan.

$\mathrm{Na}$ interação com os dirigentes de Harmony Bay, a interação também ocorre de forma distinta, sendo que com estes Theo torna-se agressivo, medindo forças com os mesmos. Insultar o psiquiatra do presídio, por exemplo, é uma liberdade que Theo toma, pois sua posição social o protege. Observa-se que os detentos não se atreveriam ao mesmo ato, pois não estão socialmente autorizados a isto. Fica evidenciado, assim, como o interlocutor, a situação imediata em que ocorre a enunciação, o contexto social e as ideologias influenciam na forma com que o discurso é estruturado.

Theo pode ser considerado a metáfora do homem totalmente civilizado, que sabe se comportar oportunamente em cada situação, isto é, representa o "camaleão" que sabe como agir em cada momento para manter-se aparentemente coeso à sociedade.

\section{Os lugares sociais}

Da mesma forma que é conferido crédito ao discurso do psiquiatra Theo Caulder, graças a sua posição social, também as ações dos guardas florestais e dos agentes penitenciários do presídio Harmony Bay são justificadas pelas posições que ocupam. Conforme observa Certeau, na sociedade moderna, costumou-se apegar-se mais "às expressões, e não mais ao que elas exprimem; aos benefícios de uma adesão, mais do que à sua realidade" (2001, p. 27). 
$\mathrm{Na}$ floresta, guardas florestais que deveriam proteger os animais silvestres os matam, sendo que o poder que lhes é imputado livra-os das responsabilidades. Igualmente, em Harmony Bay, os guardas penitenciários são tão violentos - se não mais - quanto os detentos, sendo justificados por serem os detentores do poder. É o que ocorre, por exemplo, no cotidiano, em que muitos governantes, empresários, figuras de destaque são comprovadamente corruptos, sonegadores, criminosos e, no entanto, nenhuma atitude é tomada graças ao status que possuem, vez que a própria sociedade legitima tais atitudes. Nesta perspectiva, as relações de dominação, poder e controle podem ser consideradas uma das formas de violência presentes na sociedade civilizada. Segundo Certeau (2001), as instituições "críveis" da sociedade estariam enfermas, sendo necessária uma mutação do crível. Esta mutação somente seria possível, de acordo com Certeau, por meio de uma revolução que estabelecesse novos valores para a civilização. Nota-se que a convivência de Ethan com os primatas possibilitou que seus valores fossem alterados.

As relações de dominação, via de regra, estão camufladas na sociedade. Isto fica evidente na cena em que Ethan deseja voltar para a cela, mas é Theo, o psiquiatra, quem pode dizer quando a sessão terapêutica estará encerada, apesar de ter dito que Ethan é livre para poder tomar suas próprias decisões.

Assim, pode-se afirmar que os guardas florestais, bem como os agentes penitenciários e o psiquiatra são a metáfora perfeita dos indivíduos que abusam do poder que lhes é imputado e ficam impunes, graças ao status que lhes é conferido pelo meio social, lembrando que, na visão de Certeau, "toda autoridade repousa sobre uma adesão" (2001, p. 37), isto é, uma autoridade somente é uma autoridade, pois um grupo social lhe dá crédito e legitima seu exercício de poder.

Foucault, em seus estudos, quebra com esta lógica maniqueísta em relação a um grupo formado por dominadores enquanto outro seria formado por dominados, e estabelece um conceito inovador no que se refere à noção de poder. Primeiramente, para Foucault não existiria poder por si só. Para que houvesse poder, necessariamente, precisaria haver algum tipo de relação social em que este pudesse manifestar-se. Nesta perspectiva, o poder é algo que não pode ser "detido" por alguém, ou seja, não existiriam detentores eternos do poder. Conforme observa Foucault, o poder não deve ser tomado

como um fenômeno de dominação maciço e homogêneo de um indivíduo sobre os outros, de um grupo sobre os outros, de uma classe sobre as outras; mas ter bem presente que o poder - desde que não seja considerado de muito longe - não é algo que se possa dividir entre aqueles que o possuem e o detém exclusivamente e aqueles que não o possuem e lhe são submetidos. $\mathrm{O}$ poder deve ser analisado como 
algo que circula, ou melhor, como algo que só funciona em cadeia. Nunca está localizado aqui ou ali, nunca está nas mãos de alguns, nunca é apropriado como uma riqueza ou um bem. O poder funciona e se exerce em rede. Nas suas malhas os indivíduos não só circulam mas estão sempre em posição de exercer este poder e de sofrer sua ação; nunca são o alvo inerte ou consentido do poder, são sempre centros de transmissão. Em outros termos, o poder não se aplica aos indivíduos, passa por eles. (FOUCAULT, 1979, p. 183)

O poder, para Foucault, encontrar-se-ia em todas as relações estabelecidas na sociedade. Segundo Roberto Machado (1979), em "Por uma genealogia do poder", as análises foucaultianas sobre o poder teriam deslocado do Estado o centro de referência quando o assunto discutido diz respeito às relações de poder. Machado afirma que, "Foucault, a partir de uma evidência formada pelo próprio material de pesquisa, viu delinear-se claramente uma não sinonímia entre Estado e poder" (1979, p. XI). Foucault não concorda com a posição de que o Estado seria o centro de onde o poder emana em ondas que submetem todos que estão à volta, punindo aqueles que se rebelam. Antes, fazendo o caminho contrário, partiria da periferia, que no texto "Soberania e disciplina" (1979) é metaforicamente representado pela imagem dos súditos, em direção ao centro, análogo à imagem do rei. Aliás, neste texto, notase que as análises de Foucault prendem-se nas micro-estruturas do poder, isto é, nas células como a família e a vizinhança, entre outros, opondo-se à análise marxista, que vê na burguesia a classe que sobrepujou toda a massa populacional para dela fazer uso, visando a obtenção de lucro. Foucault, observa que o sistema burguês de dominação é reflexo das formas microestruturais de dominação existentes dentro da família. Por exemplo, no que diz respeito à repressão e interdição dos loucos, Foucault observa que a burguesia somente se apoderou dos mecanismos de exclusão, pois, nestes casos, seriam economicamente viáveis. No entanto, não teria sido a burguesia que criou estes mecanismos, mas a sociedade como um todo. Citando Foucault,

não foi a burguesia que achou que a loucura devia ser excluída ou a sexualidade infantil reprimida. Ocorreu que os mecanismos de exclusão da loucura e de vigilância da sexualidade infantil evidenciaram, a partir de determinado momento e por motivos que é preciso estudar, um lucro econômico e uma utilidade política, tornando-se, de repente, naturalmente colonizados e sustentados por mecanismos globais do sistema do Estado. (FOUCAULT, 1979, p. 185)

Ou seja, não é o Estado que cria os mecanismos de controle, ele se apropria daqueles que já existem no meio social. É o poder que emana da periferia em direção ao centro.

Vale ressaltar que Ethan, ao cometer os assassinatos, é movido pela ideologia do cotidiano, pois o impulso agressivo não se apresenta como parte do sistema de convivência dos gorilas; antes, é a situação imediata de necessidade de preservação que leva Ethan a tomar 
tal atitude. Fica evidenciado que a violência é gerada mais pelo abuso de poder e dominação, características da sociedade "civilizada", que pelos instintos primitivos do homem/animais.

\section{A institucionalização do poder}

O cenário utilizado para ambientar a trama concentra-se, basicamente, em uma penitenciária para insanos, que representa, no filme, o expoente máximo de um sistema social que impõe determinados limites ao homem qualificado como "civilizado". Harmony Bay, presídio no qual Ethan é detido, lugar impróprio para a regeneração de qualquer individuo, apresenta-se, assim, como o campo de cerceamento do ser humano. O grande questionamento que pode ser estabelecido com relação a Harmony Bay é: quem são realmente os indivíduos que estão presos? Serão somente os detentos, ou será que os dirigentes e funcionários também estão presos? Levando em conta que a penitenciária pode ser comparada a um sistema de alienação total do indivíduo, pode-se arriscar a resposta de que todos que ali estão são tão detentos quanto os presidiários. O espaço penitenciário não corresponde somente ao presídio em si. A penitenciária pode ser vista como a representação de todo o mundo civilizado, que encarcera o sujeito, submetendo-o a padrões preestabelecido de comportamento com os quais não concorda, dos quais não deseja fazer parte. A prisão é o mundo civilizado, com suas normas, regras, ética e moral.

A prisão pode ser vista, também, como o local onde o indivíduo é disciplinado. Correlata a instituições como a escola e a igreja, a prisão visa tornar o individuo um ser dócil frente às instituições sociais. Dessa forma, a reclusão à penitenciária ilustra o mecanismo de controle exercido na vida social, normatizada e disciplinada, a qual reserva aos que se deslocam dos padrões de comportamento preestabelecido, mecanismos punitivos. Assim, determinados sujeitos controlam, ao passo que outros são controlados. No dizer de Foucault,

\footnotetext{
na essência de todos os sistemas disciplinares, funciona um pequeno mecanismo penal. É beneficiado por uma espécie de privilégio de justiça, com suas leis próprias, seus delitos especificados, suas formas particulares de sanção, suas instâncias de julgamento. A disciplina estabelece uma 'infrapenalidade'; quadricula um espaço deixado vazio pelas leis; qualifica e reprime um conjunto de comportamentos que escapavam aos grandes sistemas de castigo por sua relativa indiferença (FOUCAULT, 1987, p. 149).
}

E ainda: "a penalidade perpétua que atravessa todos os pontos e controla todos os instantes das instituições disciplinares compara, diferencia, hierarquiza, homogeiniza, exclui. Em uma palavra, ela normaliza” (1987, p. 153). Ora, Ethan é, na película, justamente a representação do "não normalizado, isto é, do anormal, desajustado, que precisa da 
intervenção do Estado para normalizá-lo. E o sistema de normalização do sujeito tem, na figura do psiquiatra, seu ponto máximo.

Para Foucault (1987), todo poder é relacional. Existem relações de poder que estão presentes em toda a sociedade ocidental. Historicamente, o homem ocidental construiu redes com essas relações de poder, que o aprisionam, impedindo que ocorram transformações significativas a ponto de destruir essas redes. Foucault ressalta que, desde o século XVIII, as prisões e hospícios (como Harmony Bay) são um instrumento de controle sobre os indivíduos que procuram fugir dessas relações de poder estabelecidas pela sociedade.

Sabe-se que, desde os primórdios, a mentalidade humana constitui-se por meio de imagens arquetipais, das quais resultam os mitos, que, por sua vez, tem como um de seus objetivos preservar dogmas e preceitos morais. Na antiguidade, como, por exemplo, entre os gregos, empregava-se o termo mito para referir-se a histórias que realmente teriam acontecido, importantes por seu caráter sagrado. Atualmente, a palavra mito designaria um evento fictício, uma ilusão. Nesta perspectiva, podemos chamar a idéia de "liberdade" como um dos grandes mitos da sociedade civilizada, pois, observando atentamente a discussão estabelecida no filme em análise, será possível enxergar que o homem nunca esteve tão privado de liberdade como na sociedade dita "civilizada".

\section{A regra do jogo}

Um dos sistemas de controle utilizados na trama diz respeito à utilização de um jogo de cartas (baralho). Todos os dias são distribuídas cartas entre os detentos, sendo que aquele que receber o "Ás de Ouro" tem o direito de passar algum tempo em um ambiente aberto e ensolarado. Legalmente, todos os presos deveriam ter o direito de usufruir deste beneficio. No entanto, no enredo, somente o detento que for contemplado com o Ás de Ouro é beneficiado. O sistema de sorteio, aparentemente igualitário, funciona somente na teoria, pois, na prática, é sempre um mesmo detento que tem o privilégio, haja vista que este detento toma, por meio da força física, a tal carta daquele que a tenha recebido. Há, nitidamente, a representação da "lei do mais forte", que impera nas sociedades capitalistas, onde "quem pode mais, chora menos", ou seja, o Ás de Ouro é a metáfora de um sistema de justiça falho, que aparenta ser igual para todos os indivíduos de uma mesma sociedade, mas que, na verdade, é injusto, pois beneficia somente os mais fortes.

Vale ressaltar, ainda, que ao ser questionado sobre a eficácia do método utilizado para escolher o detento que irá ter direito de passar uns minutos ao sol, o diretor do presídio argumenta que o sistema é eficaz, pois se apresenta como uma maneira de desviar a atenção 
dos detentos, sendo que, ao invés de direcionarem sua raiva contra os guardas e funcionários do presídio, a dirigem ao detento que, ao tomar a Ás de Ouro daquele que o recebera, privavaos da possibilidade de tomarem sol. Não será necessário mencionar o fato de que, na sociedade capitalista, muitas vezes, o olhar dos menos favorecidos é desviado daquilo que realmente lhes prejudica, daqueles que realmente se apresentam como seus algozes, por meio de recursos que põem em evidência fatos significativamente menores, mas que, semelhantes ao apresentado no filme, canalizam as forças dos indivíduos em uma direção que não perturbe ou ponha em risco a estabilidade dos dominadores. Norbert Elias, em sua célebre obra $O s$ estabelecidos e os outsiders, demonstra de forma bastante elucidativa como os grupos dominantes, manifestamente coesos, fazem uso de estratégias de manipulação para manterem os grupos dominados em desarmonia. Até a fofoca elenca-se, segundo Elias, dentre essas estratégias. Ou seja, a desagregação estabelecida dentre os dominados é altamente benéfica àqueles que dominam.

\section{Fuga e resistência}

No final do filme, como já foi dito no resumo do enredo, Ethan foge da prisão, voltando às florestas africanas. Esta fuga nada mais é que a representação da possibilidade de se manter fora do alienante sistema imposto pelo mundo civilizado, apesar de ser necessário muito empenho para se conseguir atingir este objetivo. A dominação que o mundo civilizado exerce sobre os indivíduos faz com que a maior parte dos sujeitos se mantenha inerte frente a situações a que poderiam reagir, o que é representado, no filme, com as cenas referentes ao gorila Goliath que, depois de enjaulado por muitos anos, apesar de ver a porta da jaula que o aprisiona aberta, não tenta fugir. A escravidão a que se reduz alguém, como no filme é exemplificado por Goliath, não deixa de ser uma forma de matar, destruir ou tornar este alguém insano e alienado. Infelizmente, os homens que sequer reagem frente às condutas impostas pelo meio social, apesar de disporem de oportunidades para isto, são todos como Goliath.

A fuga de Ethan representa que este teve coragem de quebrar is limites impostos pelos dominadores e não se reduziu a um capturado e subjugado como Goliath, antes, tornou real seu sonho de liberdade.

Uma das cenas mais impactantes do filme, que exemplifica com esmero a tênue relação que existe entre dominar (deter o poder) e ser dominado (sofrer as ações do poder), ocorre quando antropólogo subjuga o psiquiatra por meio da violência física, obrigando que o mesmo escreva em um papel o que tirou dele ao dominá-lo. O psiquiatra responde que ele 
havia tirado sua liberdade, mas Ethan argumenta que o psiquiatra nunca foi um homem livre. Theo responde então que Ethan havia lhe tirado as ilusões, resposta considerada correta por Ethan, vez que a liberdade, na perspectiva fílmica, seria apenas uma ilusão criada pelo mundo capitalista. Nesta perspectiva, ficou evidenciado que pensar que existe uma relação em que alguém domina constantemente ao passo que o outro só é dominado é uma espécie de ilusão, sendo que a relação dominar/ser-dominado pode inverter-se com um simples movimento, uma palavra, ou por meio da força física, não sendo necessário a existência de um Estado para que se efetue estas relações de poder entre indivíduos. O poder existe porque ele é produtivo, porque contribui para a formação de saberes, por que dá prazer. E neste ponto vale ressaltar que, na visão foucaultiana, o poder não apresenta somente um pólo negativo, antes, é também algo positivo, que, produz, que possibilita a formação de saberes. Citando Machado,

\begin{abstract}
não se explica inteiramente o poder quando se procura caracterizá-lo por sua função repressiva. O que lhe interessa basicamente não é expulsar os homens da vida social, impedir o exercício de suas atividades, e sim gerir a vida dos homens, controlá-los em suas ações para que seja possível e viável utilizá-los ao máximo, aproveitando suas potencialidades e utilizando um sistema de aperfeiçoamento gradual e contínuo de suas capacidades (MACHADO, 1981, p. 193).
\end{abstract}

Para Foucault, existiria um triângulo formado pelas noções de poder, saber e verdade. Nesta perspectiva, podemos dizer que existem regras, amparadas em conceitos do que vem a ser verdade ou não, que justificam as relações de poder. Foucault observa que há uma interrelação muito forte entre poder e verdade, sendo possível notar que, correlata à história do pensamento humano, existe uma história das verdades de cada época, que se interliga à história das relações de poder. De igual modo, haveria uma íntima relação entre poder e saber, sendo que todo saber seria formado em relações de poder, isto é, o exercício do poder se configuraria como um lugar de formação de saberes. Conforme afirma Machado, "o fundamental da análise é que saber e poder se implicam mutuamente: não há relação de poder sem constituição de um campo de saber, como também, reciprocamente, todo saber constitui novas relações de poder" (1981, p. 199). Logo, o poder seduz. E o jogo dominante/dominado acontece, em muitos casos, pois o dominado tem pretensões de se tornar o dominador, perpetuando o jogo ad infinitum.

Nesse prisma, um dos grandes questionamentos do filme no que se refere à dominação diz respeito ao fato de se o homem é ou não capaz de abrir realmente mão das possibilidades de dominar. Não há como se viver no mundo civilizado sem estar constantemente dominando e sofrendo dominação. Ethan declara no filme que, nas sociedades tribais, ou seja, de caçadores, plantadores e pescadores, tirava-se do mundo somente o necessário para a 
sobrevivência, sendo que, não havendo relações de lucro, não havia dominação. Nesta perspectiva, a fuga que deve ser empreendida pelo homem moderno não diz respeito somente às regras impostas pela sociedade, mas principalmente de seus próprios preceitos morais e ambições. Nesse prisma, talvez o mais difícil não seja fugir do sistema de dominação, mas preterir a possibilidade de dominar. Vale ressaltar que, via de regra, somos mais controlados que controladores, haja vista que constantemente agimos dominados por nossas ambições, pela sociedade, pelo relógio, etc. Voltar para a floresta, negando tudo o que a vida em sociedade pode oferecer, representa tanto que Ethan fugiu da dominação, quanto dispensou a possibilidade de dominar.

Em dois momentos distintos do filme, dois personagens tomam um banho de chuva: Ethan, na floresta em meio aos gorilas; e Theo, no epílogo do filme. Estes banhos de chuva ilustram a ruptura cultural repassada de uma personagem à outra, dentro da qual o homem, simbolicamente, libertar-se-ia de um pensamento condicionado para aceitar uma nova forma de pensar, questionando a cultura e a sociedade em que vive. O banho de chuva representaria uma espécie de "lavagem" por que passaram os indivíduos, a partir das quais rompem com as normas e conceitos da sociedade "civilizada".

\section{Considerações finais}

Analisando-se o filme "Instinto" nota-se que a normalidade é uma construção cultural, sendo que os indivíduos que não se enquadram dentro dos padrões da civilidade imposta pela sociedade, assim como o protagonista do filme, são rotulados como insanos, mesmo que estes apenas concebam o mundo que os cerca de maneira diferente dos demais.

A partir da análise apresentada, é possível inferir que todo o filme é arquitetado de forma que fique evidente a existência de determinadas ideologias por detrás das cenas. Aliás, a linguagem cinematográfica, da mesma forma que a linguagem verbal, via de regra é movida por alguma ideologia, ressaltando que toda e qualquer enunciação em si, por mais completa que pareça, é apenas uma parte do conteúdo que realmente se expressa com tal enunciação. Vale ressaltar que toda enunciação verbal se relaciona com o meio extraverbal, que é o elemento que complementa a enunciação.

A palavra apresenta-se, na película, como um meio de interação, haja vista que o psiquiatra somente consegue descobrir o que levou Ethan a matar os dois guardas florestais graças ao fato de ele ter começado a falar, isto é, interagir com Theo. O que se sabia antes a este respeito eram apenas especulações, suposições. É relevante o fato de que Ethan não responde objetivamente sobre o porquê de ter matado os guardas. Ao contrário, apenas narra 
sua história, sendo que, a partir desta narrativa, Theo consegue compreender o motivo que levou Ethan a cometer os assassinatos, ou seja, o psiquiatra consegue perceber os motivos que estão implícitos na narrativa.

Em todo o enredo do filme é possível observar a estreita relação existente entre o poder e a linguagem, sendo a linguagem um dos principais meios através do qual o poder se manifesta e se aloca para controlar e punir. Nesta perspectiva, a linguagem apresenta-se como o campo em que mais ficam à mostra as ideologias dos indivíduos, ideologias estas pertencentes não somente ao sujeito, mas ao grupo social do qual ele faz parte, as quais servem, via de regra, à perpetuação das relações de força, poder e dominação presentes no seio social.

\section{Referências}

BAKHTIN, Mikhail. Marxismo e filosofia da linguagem. São Paulo: Hucitec, 1999.

CERTEAU, Michel de. As revoluções do "crível". In: A cultura no plural. Campinas, SP: Papirus, 2001

COSTA, Cristina. Sociologia: introdução à ciência da sociedade. São Paulo: Moderna, 1997.

DURKHEIM, Émile. "As formas elementares da vida religiosa". In: GIANOTTI, José A. Coleção: Os pensadores. São Paulo: Abril Cultural, 1978.

ELIAS, NORBERT. Os estabelecidos e os outsiders. Rio de Janeiro: Zahar, 2000.

INSTINTO. Direção de Jon Turteltaub. Roteiro de Gerald Di Pego. Produção de Bárbara Boyle e Michael Taylor. Estados Unidos: Spyglass Entertainment \& Touchstone Pictures, 1999 (126 min.) 35mm colorido.

MACHADO, Roberto. Introdução. In: FOUCALT, Michel. Microfísica do poder. Rio de Janeiro: Edições Graal, 1979.

FOUCALT, Michel. Vigiar e punir: nascimento da prisão. Petrópolis: Vozes, 1987.

Recebido em 13 de setembro de 2018. Aceito para publicação em 31 de maio de 2019. 